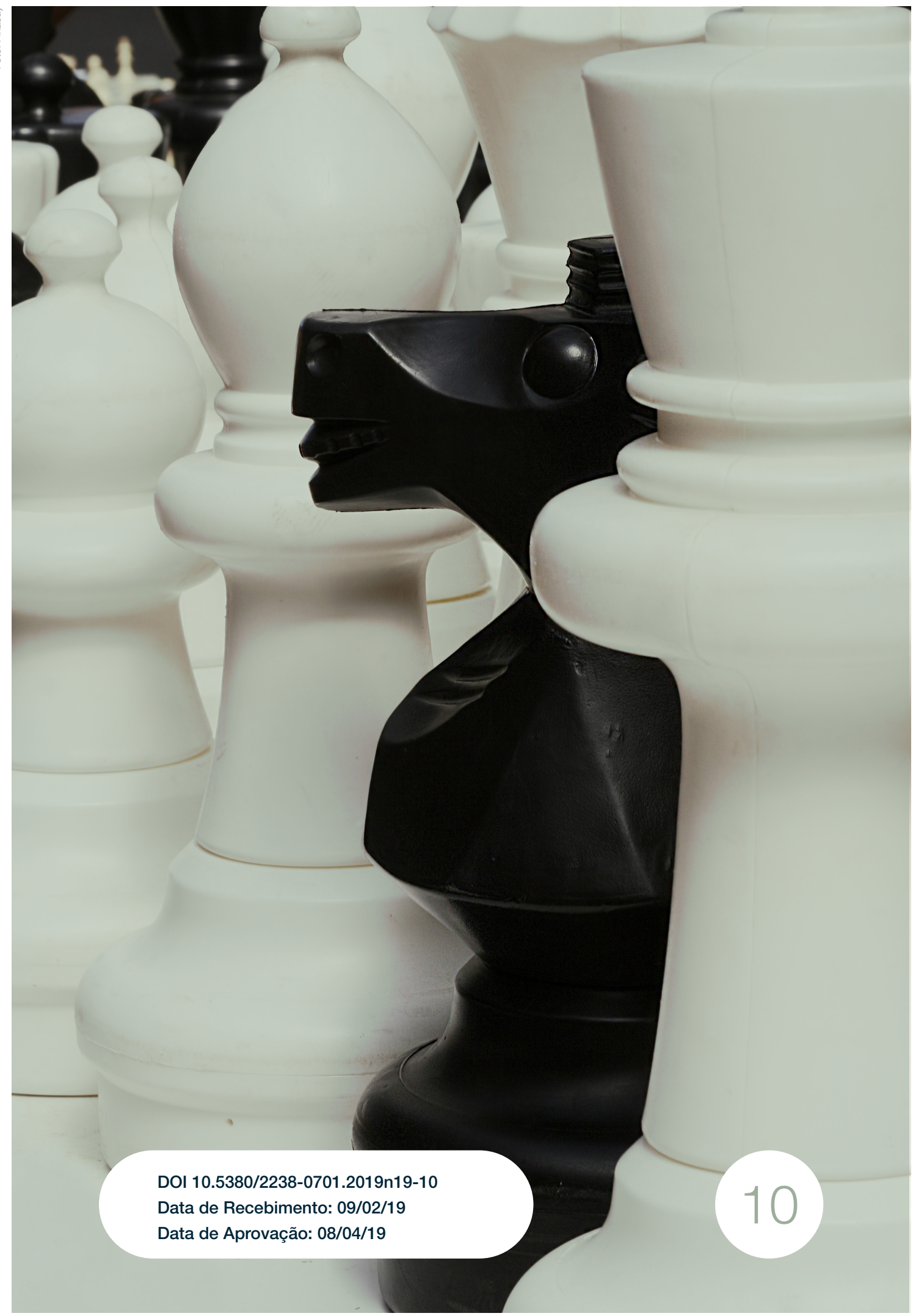


Comunicação e política: análise discursiva das narrativas construídas na eleição presidencial de 2018 no Brasil 


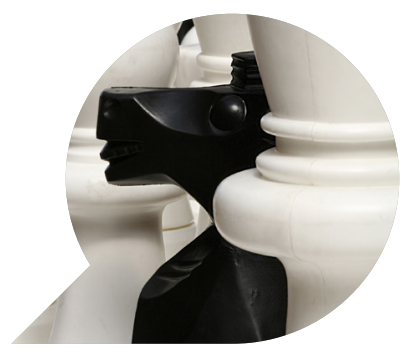

\section{COMUNICAÇÃO E POLÍTICA: análise discursiva das narrativas construídas na eleição presidencial de 2018 no Brasil}

COMUNICACIÓN Y POLÍTICA: análisis discursivo de las narrativas construidas

en la elección presidencial de 2018 en Brasil

COMMUNICATION AND POLITICS: Discursive analysis of the narratives constructed in the presidential election of 2018 in Brazil

\begin{tabular}{|c|}
\hline CAROLINE PERIN ${ }^{1}$ \\
\hline MARCIO GIUSTI TREVISOL ${ }^{2}$ \\
\hline MARIA PINTO ALMEIDA ${ }^{3}$ \\
\hline
\end{tabular}

Resumo: $\bigcirc$ artigo apresenta a relação da comunicação com a política em sociedades democráticas, sobretudo, como as produções comunicacionais na atividade eleitoral são estrategicamente organizadas para atingir o eleitorado. O objeto da pesquisa é apontar quais foram as estratégias narrativas utilizadas pelos candidatos à presidência do Brasil, Fernando Haddad e Jair Bolsonaro, em seus

1 Graduanda em Comunicação Social Habilitação em Publicidade e Propaganda, Universidade do Oeste de Santa Catarina (Unoesc). E-mail: carolineperin01@gmail.com.

2 Doutorando em Educação na Universidade de Passo Fundo (UPF). Professor da Universidade do Oeste de Santa Catarina (Unoesc). E-mail: marcio.trevisol@unoesc.edu.br.

3 Doutora em Filosofia, História e Educação pela FE da Universidade Estadual de Campinas (2001). Docente Pesquisadora do PPGE (Unoesc/SC). E-mail: malu04@gmail.com. 
programas eleitorais, no ano de 2018. A metodologia é exploratória, com a utilização da análise do discurso. O universo da pesquisa são os programas eleitorais produzidos por ambos os candidatos, entre os meses de agosto e outubro, os quais lideraram a corrida eleitoral. Pela análise empregada, é possível apontar que os candidatos utilizaram como narrativas discursos ideológicos alicerçados em valores, como: corrupção, felicidade, esperança, medo, etc. Em ambas as campanhas, é perceptível a universalização de ideais que pretendem reafirmar certas posturas sociais, de forma lacunar e de realidade invertida.

Palavras-chave: Narrativa. Estratégia. Ideologia. Sentido. Eleição.

Resumen: El artículo presenta la relación de la comunicación con la política en sociedades democráticas, sobre todo, como las producciones comunicacionales en la actividad electoral son estratégicamente organizadas para atingir el electorado. El objeto de la investigación es apuntar las estrategias narrativas utilizadas por los candidatos para la presidencia de Brasil, Fernando Haddad y Jair Bolsonaro, en sus programas electorales, en el año de 2018. La metodología es exploratoria, con la utilización del análisis del discurso. El universo de la investigación son los programas electorales producidos por los dos candidatos, entre los meses de agosto y octubre, los cuales lideraran la corrida electoral. Por el análisis empleado es posible apuntar que los candidatos utilizaron como narrativas discursos ideológicos basados en valores, como corrupción, felicidad, esperanza, miedo, entre otros. En ambas las campañas, es perceptible la universalización de ideales que pretenden reafirmar ciertas posturas sociales, de manera incompleta y realidad invertida.

Palabras clave: Narrativa. Estrategia. Ideología. Sentido. Elección.

Abstract: The article presents the relationship of communication with politics in democratic societies, especially as the communication productions in the electoral activity are strategically organized to reach the electorate. The object of the research is to point out the narrative strategies that the candidates and parties used to presidency Fernando Haddad the Jair Bolsonaro in Brazilian program 
in the year 2018. The methodology is exploratory, using discourse analysis approach. The research universe is the program produced by the two candidates who were leading the race, in between the month of August and October, which were leading the electoral run. From the analysis used it is possible to indicate that the candidates used as narratives, ideological discourses based on values such as: corruption, happiness, hope, fear, etc. In both campaigns, it is noticeable the universalization of ideals that intend to reaffirm certain social positions, in a lacunar and inverted reality.

Keywords: Narrative. Strategy. Ideology. Sense. Election.

\section{Introdução}

Um dos elementos importantes na sociedade contemporânea é a relação tensa entre política e comunicação. Nesse sentido, os recursos comunicacionais, como propaganda ou marketing, são utilizados para produzir sentidos e convencer os eleitores sobre suas propostas. As produções midiáticas lançam narrativas discursivas construídas e estrategicamente definidas com a intenção de convencer e produzir uma opinião pública favorável para determinado político ou partido. Por isso, analisar as narrativas discursivas significa compreender suas relações de poder e de como se constroem conhecimentos e verdades.

Nessa perspectiva, o artigo tem como foco as eleições presidenciais de 2018 no Brasil. O objetivo é compreender e decifrar quais as estratégias narrativas - ou discursivas, que os candidatos Fernando Haddad e Jair Bolsonaro utilizaram em seus VTs (programas eleitorais), dando-Ihes créditos para disputarem o segundo turno. Para responder o objetivo primário, empregamos a técnica metodológica de análise do discurso, proposta por Orlandi (2002). A análise do discurso é um método de pesquisa qualitativa, com investigação exploratória, bibliográfica e documental, no qual se tem como objetivo entender a produção dos significados dos textos a serem analisados. Essa técnica analisa a linguagem tanto do senso comum quanto dos discursos políticos. A abordagem metodológica nos permitiu responder ao problema que se caracteriza pelas seguintes indagações: quais são as estratégias comunicacionais utilizadas 
pelos candidatos à presidência? O que pretendiam universalizar em seus discursos? Quais elementos caracterizam suas narrativas midiáticas? As respostas aos questionamentos estão diluídas em duas partes no artigo; a) na primeira parte, pontuamos os elementos que caracterizam as narrativas produzidas pelos meios de comunicação, estabelecendo um diálogo com as definições de ideologia e produção da opinião pública; b) na segunda parte, apresentamos a análise dos VTs coletados durante a campanha eleitoral de 2018 que ocorreu no Brasil. Por motivos de espaço, selecionamos apenas alguns VTs, obedecendo como critérios a distribuição equitativa no tempo, isto é, apanhamos três VTs de cada candidato, um no início, um no meio e outro ao final do pleito eleitoral.

Portanto, tendo como base os dois candidatos mais bem colocados no processo eleitoral: Fernando Haddad (PT) e Jair Messias Bolsonaro (PSL), pudemos apontar como narrativas ideológicas a tentativa de universalizar, por um lado, a figura heroica do ex-presidente Lula e, por outro lado, um discurso ideológico conservador, que se sustentou sobre a prerrogativa da corrupção, ligando-a ao PT. Embora tenham posições diferentes do ponto de vista político, o artigo apontou para a construção de narrativas eleitorais feitas pela comunicação como estratégias publicitárias.

\section{Ideologia como narrativa: a formação da opinião pública a partir dos meios de comunicação}

A opinião pública é caracterizada pela participação popular com grande força de expressão nos temas abordados e vinculados aos estereótipos envolvendo aspectos comportamentais de todos os sujeitos e, quando estes se identificam, a opinião passa a ser instituída de forma individual, grupal, e, posteriormente, opinião da maioria do público. A pluralidade a respeito desse assunto ocorre pela sociedade e como ela desenvolveu formas a fim de transmitir seus conhecimentos.

Segundo Melo (1998, p. 203), a estrutura da expressão conceitual referente à opinião pública significa: "OPINIÃO - juízo de valor, julgamento, tomada de posição, formulação de uma atitude; PÚBLICA - do povo, da população. [...] chegamos ao seguinte conceito: OPINIÃO PÚBLICA - juízo de valor formulado pelo povo em torno de um fato concreto." 
É possível analisar como outros autores também abordam o conceito sobre a opinião pública. Augras (1974, p. 12) aborda que "no nível individual a opinião pública confunde-se com atitude. No nível coletivo, aparece como entidade mítica: a opinião pública é o sentimento do povo."

\begin{abstract}
A mesma variedade semântica observa-se a propósito do adjetivo "público" que pode qualificar ao que se refere ao "povo" considerando ao seu conjunto (e, então, significa "comum", "geral”); opõe-se, igualmente, a "privado" e designa o que, formalmente é "aberto a todos" (por exemplo, um jardim "público" ou um escritor "público"*), isto é, na realidade, a todos os que o desejarem ou puderem, ou ainda o que pertencem ao Estado e pressupõem um "interesse coletivo" ou "geral" ("domínio público", "direito público", etc.). No entanto, esse adjetivo tem, igualmente, um sentido mais diretamente político e designa também "o que não é secreto", o que deve ser feito "às claras", assim como as pessoas que exercem uma função "oficial" ("homem público") e, enfim, por extensão, o que é "conhecido por todos" ("notório"). (CHAMPAGNE, 1998, p. 45).
\end{abstract}

Champagne (1998) faz colocações referentes ao adjetivo "público", considerando tal expressão ligada diretamente aos assuntos políticos. Dessa forma, a "opinião pública" é utilizada para compreender o eleitorado em época de eleições, processo muito utilizado pelos grupos de sondagens. Figueiredo e Cervellini (1996, p. 15) citam que um grupo de "analistas preferem compreender a opinião pública como o resultado que se verifica nas pesquisas: só está em sintonia com a opinião pública quem age de acordo com o que mostram as pesquisas." Essa relação da opinião pública colocada pelos analistas e citada como exemplo pelo autor, está interligada à democracia e ao período de eleições, em que o voto tem o mesmo valor, independentemente do sujeito e suas condições sociais, econômicas, políticas e culturais, considerando a soma de todos os votos, como opinião pública. Nessa definição, a produção dos sentidos passa a ser esquematizada de forma estratégica, a fim de disseminar ideias que influenciem a opinião pública por meio da comunicação de massa.

Estratégias que são utilizadas para implantar ações com intuito de destacar um nome e suas qualidades juntos aos eleitores da forma 
mais clara e definitiva possível, levando nestas ações de conteúdo que façam o eleitorado assimilá-las com o objetivo de, no primeiro instante, eleger o dono do nome a um cargo eletivo, e posteriormente alimentar este conceito e defendê-lo. (MANHANELLI, 1988).

Essas estratégias são traçadas com escopo de formar a opinião pública que, junto com a propaganda eleitoral, trabalha para influenciar a opinião dos indivíduos. Para Manhanelli (1988, p. 41), "a propaganda tem o papel de valorizar ideias e indivíduos, mediante processos bem delimitados, e de promover a fusão da ideologia política." Com capacidade de formar valores, propagar ideias e influenciar comportamentos, a propaganda e o marketing, juntamente com os meios de comunicação, produzem, historicamente, narrativas claras de diferenciação para determinados grupos específicos, que vão ao encontro do discurso proferido, estes constituídos por um sistema de representação, categorias, linguagens e conceitos.

A narrativa política é trabalhada a fim de universalizar uma ideia, que jamais deve ser compreendida de forma transparente. Estratégias são utilizadas para induzir, persuadir e seduzir os indivíduos. Segundo Orlandi (2002, p. 42), "consequentemente, podemos dizer que o sentido não existe em si, mas é determinado pelas posições ideológicas colocadas em jogo no processo sócio-histórico em que as palavras são produzidas." As narrativas empregadas nos discursos políticos constroem o espaço dos indivíduos por meio dos significados e sentidos engajados pela ideologia, a qual trabalha a legitimidade do poder e, ao mesmo tempo, a problemática dos atores sociais, reproduzindo e reformulando a realidade social, garantindo exclusividade na disseminação de determinadas ideias, no intuito de abranger um grande número de eleitores. Esse processo ocorre pela transmissão das formas simbólicas inseridas no contexto de comunicação de massa, que são mediadas em três campos objetivos. Thompsom (1995, p. 392) expõe como "enfoque tríplice", pois abrangem três aspectos:

O primeiro aspecto é o da produção e transmissão ou difusão das formas simbólicas, isto é, o processo de produção das formas simbólicas e de transmissão e distribuição via canais de difusão seletiva. [...] O segundo aspecto é a construção da mensagem dos meios de comunicação de massa. Essas mensagens transmitidas [...] são 
produtos que estão estruturados de diversos modos, são construções simbólicas complexas que apresentam uma estrutura articulada. O terceiro aspecto da comunicação de massa é a recepção e apropriação das mensagens dos meios. Essas mensagens são recebidas por pessoas, e grupo de pessoas que estão situados dentro de circunstância sócio-históricas específicas, e que empregam os recursos disponíveis a eles a fim de compreender as mensagens recebidas e incorporá-las na sua vida cotidiana.

Esses aspectos são estabelecidos por meio da abstração de outros aspectos que alimentam a comunicação de massa. É possível analisar, de acordo com Thompson (1995), como os meios de comunicação de massa trabalham o caráter ideológico das mensagens comunicativas. $\bigcirc$ primeiro aspecto - produção e transmissão - está relacionado às instituições e relações sociais, em que as mensagens têm seu princípio de produção e difusão como produtores. O segundo aspecto - construção das mensagens - mediante a fatores, constitui a mensagem e produz significados simbólicos. Já o terceiro aspecto - recepção e apropriação da mensagem - inclui considerações sócio-históricas, que passam a ser recebidas pelo indivíduo, abrigando-as e incorporando-as em sua vida (THOMPSON, 1995).

Nessa perspectiva, os caminhos das diferentes abordagens trabaIham diversos temas, a fim de compor uma interpretação de rápida compreensão, em que as narrativas articulam o sentido dos discursos de forma possuidora, organizacional e social, por meio do contexto histórico, político, econômico, cultural e ideológico, o qual reflete um sistema de valores e interesses em nível nacional. Chauí (1990, p. 64) destaca uma questão fundamental a respeito da propriedade de universalização: as relações dos sujeitos com base na ideologia. Para Chauí (1990, p. 64):

[...] as relações sociais são representadas imediatamente pelas ideias de maneira invertida. Com efeito, à medida que uma forma determinada da divisão social do trabalho se estabiliza, se fixa e se repete, cada indivíduo passa a ter uma atividade determinada e exclusiva que the é atribuída pelo conjunto de relações sociais, pelo estágio das forças produtivas e, evidentemente, pela forma da propriedade. Cada um não pode escapar da atividade que lhe é socialmente imposta. 
que não há diferenças de posições e interesse, em que as propostas apresentadas têm como escopo beneficiar todos os eleitores e brasileiros, trabalhando os interesses gerais de toda a população. No entanto, os valores de quem exerce o poder são ampliados a quem ele domina, determinando o que é necessário que os dominados façam para que haja uma organização social (ORLANDI, 2002).

As características ideológicas mencionadas são trabalhadas por narrativas que apresentem ideias, propostas e projetos de determinado grupo ou classe, ocultando acontecimentos que estão eminentemente ligados à satisfação de suas realizações. Nessa perspectiva, dentro da Análise de Discurso, a ideologia é um dos fatores que contribui para a construção contextual do discurso, uma vez que por meio das categorias de análise trabalhadas é possível compreender o sentido em que o texto foi construído e estruturado, a fim de atingir determinado objetivo e, ao mesmo tempo, perceber como as estratégias são articuladas no início, meio e fim da campanha. As narrativas utilizadas pelos candidatos trabalham uma trajetória oposta e com diferentes personalidades políticas, as quais refletem nos eleitores valores de admiração, devoção de um líder, esperança, medo, corrupção e felicidade, valores significativos para os eleitores, os quais são apresentados conforme suas expectativas de mudança, de desejos e anseios por meio da ideologia a qual cada grupo ou classe defende.

\section{Análise de dados: narrativas ideológicas utilizadas na campa- nha presidencial 2018 no Brasil}

Como objeto de pesquisa selecionamos três VTs de cada candidato, atribuindo o seguinte critério de seleção: análise dos VTs dos dois primeiros candidatos colocados na corrida eleitoral no primeiro turno. A seleção aconteceu no período de 31 de agosto a 04 de outubro de 2018, com a escolha de três programas eleitorais por candidato, sendo que o primeiro programa foi veiculado no início da campanha eleitoral, o segundo veiculado no meio da campanha eleitoral e o terceiro programa veiculado ao final da campanha eleitoral do primeiro turno. A análise do discurso trabalha com o método de pesquisa qualitativa, com investigação exploratória, bibliográfica e documental, apresentando como objeti- 
vo entender a produção dos significados dos textos a serem analisado. A análise do discurso busca analisar a linguagem dentro dos discursos políticos, e a abordagem metodológica, nesta pesquisa, permitiu responder ao problema, que se caracteriza pelas seguintes indagações:

Quais são as estratégias comunicacionais utilizadas pelos candidatos à presidência? O que pretendiam universalizar em seus discursos? Quais elementos caracterizam suas narrativas midiáticas? As respostas aos questionamentos estão diluídas em duas partes no artigo; a) na primeira parte são pontuados os elementos que caracterizam as narrativas produzidas pelos meios de comunicação, estabelecendo um diálogo com as definições de ideologia e produção da opinião pública; b) na segunda parte se apresenta a análise dos VTs coletados durante a campanha eleitoral de 2018 que ocorreu no Brasil.

Dessa forma, foi possível identificar as abordagens e narrativas que foram trabalhadas ao longo da campanha eleitoral, pelos candidatos Fernando Haddad, do Partido dos Trabalhadores (PT) e Jair Messias Bolsonaro, do Partido Social Liberal (PSL).

O primeiro programa eleitoral audiovisual produzido pelo Partido dos Trabalhadores (PT) foi veiculado no Programa Eleitoral Gratuito, na tarde do dia 01 de setembro de 2018. O programa eleitoral foi apresentado sem presidente. O discurso inicia-se com o locutor discorrendo um "informativo" referente à cassação da candidatura de Luís Inácio Lula da Silva: nele, o uso da sigla ONU é trabalhado para sustentar e apoiar o discurso, a fim de manter as ideias do partido e a popularidade do ex-presidente que, posteriormente, poderá transferir seus votos para o seu sucessor. O discurso enfatiza que a cassação de Lula foi um golpe contra a democracia. Esse discurso é mantido, a fim de desconstruir a visão de repúdio e rejeição de grande parte do eleitorado.

Ao explorar o intradiscurso, trabalha-se a coerência dos fatos, fortalecendo e justificando com argumentos, por meio da sensação de "vitimização" e, ao mesmo tempo, de inquietação, não aceitando a negação da candidatura do ex-presidente Lula, trabalhando a ideia de que o Tribunal Superior Eleitoral efetuou um golpe contra o povo.

Em seguida, o locutor conclui a sua fala trazendo o slogan do partido: "Coligação ‘o povo feliz de novo'. 13!" (informação verbal). O slogan: "O povo feliz de novo" é utilizado para fortalecer a campanha, em um momento que o Brasil passa por uma etapa difícil dentro da política, 
na qual a sociedade expressa o cansaço e a indignação das gestões passadas, um slogan simbólico que se constata a utilização à categoria ideológica - a universalização -, resultado de uma abstração (ARANHA, 2003). Trabalhando a ideia de que em alguns momentos a gestão do Partido dos Trabalhadores foi positiva e que o "povo era feliz", o slogan se sustenta por apelo de lembrança, sendo possível compreender que houve uma crise de esperança, mas que é possível voltar à felicidade, por meio da positividade e perseverança.

O grito "Lula Livre" identifica-se à categoria ideológica - o parecer social -, em que é trabalhada a aparência social, que não é algo falso ou errado, mas é o modo como o processo social aparece para a consciência direta dos homens (CHAUÍ, 1990, p. 104-105). Sendo Lula um preso político e não um criminoso, trata-se de uma manifestação interligada à liberdade de Lula e à justiça ao trabalho, que vai ao encontro da imagem histórica do ex-presidente, visto como maior líder político brasileiro, e, independentemente dos fatos e acontecimentos dos últimos meses, parte dos indivíduos idolatra Lula, considerando-o como referência política.

É possível analisar a estratégia de utilizar Adolfo Pérez Esquivel, argentino ativista dos direitos humanos, o qual foi agraciado com o Prêmio Nobel da Paz, apoiando Lula, possuidor de um grande poder simbólico no mundo - identificando-se aqui a categoria ideológica à naturalização exposta por Aranha (2003, p. 62). Esquivel trabalha com a estratégia de testemunho, a fim de produzir legitimidade e veracidade por meio das personalidades de referências. Adolfo Esquivel, grande representante, com notória autoridade internacional, com expressiva credibilidade para influenciar o público receptor, no caso o eleitor, posicionou-se contra a prisão de Lula, contra a candidatura de Bolsonaro e se fez porta-voz na marcha "Lula Livre".

Durante o discurso trabalhado no programa eleitoral, é possível perceber que em nenhum momento é enfatizado quem é o presidente e quem é vice. Logo, o jingle trabalha a categoria ideológica - a lacuna ao unir a universalização e abstração, em que se obtém uma realidade oculta, que não possui liberdade para exibir algo concreto (ARANHA, 2003, p. 62). O jingle traz Lula como presidente, de forma abstrata, e Haddad como vice-presidente. O jingle "É o Brasil feliz de novo" trabaIha a responsabilidade de atender às expectativas do "povo", de vê-lo feliz e satisfeito novamente. No primeiro VT, é possível identificar uma 
estratégia narrativa utilizada pelo Partidos do Trabalhadores. Em um primeiro momento, é trabalhada uma narrativa que assegura a inocência do ex-presidente Lula e mantém a militância unida em torno da figura do líder político. O segundo passo da narrativa é produzir um sentimento de perseguição e ligar a figura do ex-presidente Lula à imagem de Fernando Haddad, no sentido de afirmar que Lula é Haddad e Haddad é Lula. Essa construção ideológica, por um lado, possui como objetivo formar uma opinião pública que blinde o Lula da corrupção e conserve sua imagem política como um mártir e, por outro lado, esforça-se para traduzir e transferir o eleitorado do ex-presidente Lula para Fernando Haddad. Nesse caso, a construção da narrativa atribui ao sistema político-judiciário brasileiro a culpa pela perseguição e retirada da candidatura política do Lula.

O segundo programa audiovisual, analisado e produzido para a campanha eleitoral, já apresenta Fernando Haddad como candidato à Presidência da República, pelo Partido dos Trabalhadores (PT). O VT foi veiculado no Programa Eleitoral Gratuito na noite do dia 18 de setembro de 2018. No início do VT, o fragmento diz o seguinte: "Começa agora o programa Haddad, 13." (informação verbal). A voz da criança faz o eleitor prestar atenção no programa eleitoral, a fim de fazê-lo recordar seu tempo de criança. Nesse momento, é trabalhada a categoria ideológica - a universalização -, na qual a voz da criança e a imagem de Haddad vão ao encontro da família brasileira. Em seguida, Lula discorre o seguinte Fragmento:

Em 500 anos de Brasil, nós nunca tivemos alguém da capacidade de Haddad pra fazer o que foi feito pra educação nesse país. Eu tô cansado de encontrar gente filha de pequeno produtor formado em Medicina, formada em engenharia, em Psicologia, em Filosofia. E esse homem é o responsável por isso. (informação verbal).

Enquanto Lula realiza a sua fala, alguns momentos da biografia de Haddad são trabalhados por meio das imagens. Lula utiliza-se do interdiscurso e critica os governos anteriores que não tiveram a capacidade de proporcionar uma educação melhor e de qualidade para os jovens brasileiros, mas afirma que com Haddad foi diferente, o ex-presidente 
enfatiza a eficiência, rendimento e potencial de Haddad em sua gestão como Ministro da Educação. Segundo Fiorin (1988, p. 34), "as visões de mundo não desvinculam da linguagem, porque a ideologia é vista como algo imanente à realidade é indissociável da linguagem." Conforme Orlandi (2002, p. 48), "[...] aparece como efeito da relação necessária do sujeito com a língua e com a história para que haja sentido. [...] assim as imagens que permitem que as palavras 'colem' com as coisas."

Ao finalizar o programa eleitoral entra o jingle: "Haddad é Lula, é 13, é o povo. É o Brasil feliz de novo. 13!" (informação verbal, grifo extraído do VT). Nesse programa eleitoral, é possível perceber a mudança do jingle em relação ao primeiro VT analisado, uma vez que neste se tem a compreensão de que Haddad é candidato a presidente, no entanto, no jingle é apresentada a referência que Haddad é representante de Lula.

O terceiro programa audiovisual analisado e produzido para a campanha eleitoral do candidato Fernando Haddad foi veiculado no Programa Eleitoral Gratuito na tarde do dia 4 de outubro de 2018. O programa tem início com o locutor, que discorre o seguinte fragmento: "Começa agora o programa Haddad presidente, 13. O ministro de Lula que abriu as portas da universidade para todos. O prefeito que humanizou a cidade de São Paulo. O presidente que vai fazer o Brasil feliz de novo." (informação verbal).

Em seguida, o candidato Fernando Haddad profere um fragmento com uma fala semelhante a do ex-presidente Lula, quando usa a expressão "Minhas amigas e meus amigos", ao informar que o dia das eleições está próximo. Em seguida, discorre uma crítica ao candidato Jair Bolsonaro do Partido Social Liberal (PSL), quando enfatiza que a coligação quer um Brasil de paz: "Queremos um Brasil de paz para todas as famílias. E paz se constrói garantindo direitos. Direito a três refeições por dia, direito a emprego, salário justo, saúde, educação e oportunidade para todos." Nessa passagem, identifica-se a categoria ideológica - a universalização, efeito de abstração (ARANHA, 2003, p. 62). Em seguida, o candidato Fernando Haddad diz o seguinte:

Eu assumo um compromisso com você: vou fazer um país com oportunidades para todos. Mas, para isso, preciso de seu apoio e de seu voto no 13. Nesta reta final, converse com seus amigos e com a família. Lembre-se: urna não é lugar de depositar ódio, é o lugar de depositar esperança. Eu acredito no Brasil e no povo brasileiro. Nós já fize- 
mos esse país feliz uma vez. Juntos vamos fazer o país feliz de novo. Um forte abraço e que Deus abençoe a todos. (informação verbal).

A construção narrativa apresentada nesse VT vem ao encontro do contexto dessa eleição. Primeiro, o grande número de fake news que colonizaram os debates nas redes sociais e, em segundo, o constante discurso de endurecimento contra a corrupção que carregou um sentimento de ódio que separou o eleitorado. Os puros e impuros. É importante esclarecer que essas estratégias publicitárias de separação e de identificação de grupos resultantes já foram amplamente utilizadas nas duas grandes guerras mundiais. Segundo Laswell (1978), trata-se de uma estratégia de convencimento de propostas construir discursos segregatórios dos puros e perfeitos contra os impuros e imperfeitos, que devem ser perseguidos e exterminados. Nesse sentido, Fernando Haddad (PT) utilizou de uma narrativa de aproximação aos valores democráticos. Essa aproximação e defesa da democracia permitiu criticar o candidato oponente e neutralizar os tons de crítica à corrupção, que foram o ponto alto da campanha dos demais candidatos à presidência contra o PT.

É importante considerar que a campanha de Haddad (PT) apresentou algumas particularidades e características, dentre elas podemos destacar: a) um forte apelo aos organismos internacionais, como a ONU. Essa posição pode ser observada no seguinte fragmento:

\footnotetext{
Atenção: a ONU já decidiu que Lula poder ser candidato e ser eleito como presidente do Brasil. Mesmo assim, a vontade do povo sofreu mais um duro golpe com a cassação da candidatura de Lula pelo TSE.A coligação "povo feliz de novo" estrará com todos os recursos para garantir o direito de Lula ser candidato. Não vão aprisionar a vontade do povo (INFORMAÇÃO VERBAL)
}

A defesa do ex-presidente Lula é central em todo o processo construtivo da campanha. No entanto, a estratégia apresentada evidencia a sustentação do senso comum ao aplicar o conceito "Vontade do povo". Em segundo lugar, a sustentação do parecer da ONU, por parte do Partido dos Trabalhadores, coloca em ameaça a própria democracia ao desqualificar um dos poderes do Estado Democrático. A tentativa é produzir 
uma opinião pública favorável ao argumento de que Lula e o Partido do Trabalhadores são perseguidos políticos. Cabe ressaltar, que esse tipo de estratégia eleitoral (publicitária) coloca a figura de Fernando Haddad como coadjuvante; b) uma segunda particularidade é a defesa incondicional do ex-presidente Lula. Mesmo preso, a proposta estratégica do PT é colocar a figura do ex-presidente como autoridade política do Brasil que elevou os padrões de desenvolvimento. Isso é observado no slogan "Lula Livre"; c) outra particularidade presente na campanha de Haddad (PT) foi a defesa da democracia e a tentativa de colar sua imagem pessoal e do próprio partido, aos movimentos contemporâneos, como o feminismo. Embora tenha aparecido como estratégia, na prática, não emplacou, pois, inclusive as pautas do próprio Partido dos Trabalhadores não são próprias de movimentos contemporâneos.

$\mathrm{Na}$ maior parte do processo eleitoral, o Partidos dos trabalhadores $(\mathrm{PT})$ adotou como estratégia colocar o seu candidato em segundo plano. Essa é uma estratégia única, não experimentada em outro país democrático. Um candidato a presidência (Fernando Haddad) que atua como um representante de um ícone (Lula) que não pode ser candidato a presidência. Essa estratégia, empobreceu o debate político porque não apresentou uma proposta de governo. Outra questão foi a incapacidade de traduzir os discursos produzidos em âmbito televisivo para uma prática social. Em outras palavras, o candidato Haddad (PT) não disseminou com robustez seu discurso nas redes sociais. A produção de sentido ficou restrita em uma relação verticalizada e não horizontalizada. Por fim, é importante assinalar que ao final do processo eleitoral o próprio PT modificou suas cores tradicionais, sobretudo, o vermelho e adotou as cores do Brasil, em destaque, o amarelo. Uma estratégia que evidência o reconhecimento de um anseio popular. A última tentativa, foi de apagar a simbologia vermelha que por décadas caracterizou o Partido dos Trabalhadores. Um outro ponto importante para destacar que a narrativa construída pelo candidato a presidência Haddad foi de defesa do ex-presidente Lula e do próprio partido. Nesse sentido, o candidato não elaborou uma estratégia publicitária e nem construiu uma narrativa que fortalecesse de forma orgânica a sua imagem. Ao invés de construir um caminho viável de poder, tendo o candidato Haddad como protagonista, foi utilizada a estratégia política de defesa e de proteção do Partido (PT) e do próprio Lula. 
Nesse mesmo procedimento de análise, com os mesmos critérios, analisa-se a estratégia narrativa da campanha de Jair Messias Bolsonaro. Para iniciar, é importante destacar algumas particularidades de sua campanha: a) não coligou e nem recebeu declaradamente apoio político de nenhum dos grandes partidos no Brasil; b) foi candidato de um partido pequeno (PSL), que não tinha qualquer representatividade considerada no cenário nacional; c) constrói-se como candidato, a partir de um discurso forte contra as políticas públicas (especialmente, as afirmativas); d) forte defesa do Estado Liberal em consonância com a defesa dos interesses dos grandes grupos empresariais; e) forte discurso contra a corrupção; f) forte crítica e perseguição ao projeto de sociedade defendido pelo PT; g) defesa de sua candidatura como um salvador da pátria que recebeu uma missão; h) defesa de sua imagem como a inovação e possibilidade de acabar com tudo aquilo que é tradicional; i) campanha consolidada nas redes sociais e não em veículos tradicionais; j) crítica aos grandes veículos de comunicação, ao judiciário e ao poder legislativo. Seu desempenho ocasionou, como definem alguns cientistas políticos, uma "onda Bolsonaro", com a vitória de governadores e representantes das casas legislativas que eram desconhecidos.

O primeiro programa eleitoral audiovisual produzido para a campanha eleitoral do candidato à presidência, Jair Messias Bolsonaro, pelo Partido Social Liberal (PSL), foi veiculado no Programa Eleitoral Gratuito na tarde do dia 01 de setembro de 2018. O fragmento proferido pelo candidato durante os oitos segundos, diz o seguinte: "Vamos caminhar juntos em defesa da família e da nossa pátria. Rumo à vitória." (informação verbal).

Ao diluir o fragmento se percebe que candidato usufrui de palavras-chave que significam muito a cada indivíduo, indo ao encontro do companheirismo, lealdade e, principalmente, da afeição pelo eleitor. Augras (1974) coloca que esse tipo de discurso trabalha com estereótipos discursivos, os quais atendem a necessidade e os interesses da sociedade, padronizam e dominam o comportamento dos indivíduos, discursos emocionais e irracionais que a propaganda explora. Segundo Thompson (1995), a construção das mensagens ocorre por meio de fatores que constituem a mensagem e produzem significados simbólicos.

Logo, o termo: "Rumo à vitória" identifica-se à categoria ideológica - a universalização -, resultado de uma abstração, em que o candida- 
to demonstra confiança ao proferir a frase, trabalhando um efeito de vencedor. Além desse aspecto, a campanha à presidência do PSL, encabeçada pelo Jair Messias Bolsonaro, em televisão e rádio, não apresentou propostas de governo claras e suficientemente explicadas. Suas propostas de governo, quando apresentadas, configuravam-se como "manchetes" simples e sem formato. No pouco tempo que possuía de televisão e rádio, concentrou-se em elaborar ataques e críticas a todo o sistema político brasileiro.

O segundo programa eleitoral audiovisual, produzido para a campanha eleitoral do candidato à presidência, Jair Messias Bolsonaro, pelo Partido Social Liberal (PSL), foi veiculado no Programa Eleitoral Gratuito na tarde do dia 08 de setembro de 2018. O programa eleitoral foi produzido em apoio à recuperação do candidato, em razão do atentado que sofreu no dia 6 de setembro de 2018, durante a campanha eleitoral em Juiz de Fora - Minas Gerais. Bolsonaro foi esfaqueado no momento que era levado por apoiadores durante a passeata no centro da cidade. Em seguida, o suspeito foi detido em flagrante ao ser segurado por populares e identificado como Adelio Bispo de Oliveira (GAZETA DO POVO, 2018).

Diante do acontecimento, Bolsonaro ficou "impossibilitado" de fazer os programas eleitorais para que, posteriormente, pudesse passar no Horário Eleitoral Gratuito. No entanto, a sua equipe de comunicação "conduziu a campanha", discorrendo força ao candidato: "O povo brasileiro caminha unido em oração pela vida do nosso Jair Messias Bolsonaro. Deus acima de todos. Muito obrigado!" (informação verbal).

O intradiscurso é formado pela atualidade em que a formulação é construída de acordo com o momento e condições estabelecidas ao enunciador (ORLANDI, 2002, p. 32-33). O acontecido preocupou a população brasileira e com o decorrer do tempo potencializou a imagem do candidato, por meio da comoção nacional, diminuindo um dos fatores negativos, como a rejeição, que grande parcela da sociedade tinha perante o candidato.

O sujeito então busca definir tudo o que está próximo de si, utiliza de uma ideologia forte, quando cita: "Deus acima de todos. Muito obrigado!" (informação verbal). Do ponto de vista ideológico, a estratégia de colocar Deus acima de todos aponta para a tentativa de absorver o público eleitor católico e favorecer os interesses específicos de certos 
grupos religiosos no Brasil. É um discurso agradável aos cidadãos que não querem mudanças e se guiam pelo autoritarismo-conservador. Ideologicamente, transfere um sentido de sociedade conversadora, que não admite contradições, nem críticas. Demonstra respeito e consideração ao eleitor. Durante o programa em apoio ao Jair Bolsonaro, mantém-se fixa na tela a imagem do candidato com a hashtags \#FORÇAJAIR, utilizada para criar uma interação entre o conteúdo com os demais usuários das redes sociais, uma forma que o candidato pode ter conhecimento de quem "aderiu às hashtags", o que comentaram e compartilharam a respeito do assunto, para a produção de novos programas.

O terceiro programa eleitoral audiovisual, produzido para a campanha eleitoral do candidato à presidência, Jair Messias Bolsonaro, pelo Partido Social Liberal (PSL), foi veiculado no Programa Eleitoral Gratuito na tarde do dia 04 de outubro de 2018. O locutor profere o seguinte fragmento: "Mentiras, calúnias, perseguição, tentaram até tirar a vida dele, o sistema quer se manter no poder, o sistema não quer Bolsonaro. Mas o povo quer. E quem decide é o povo." (informação verbal).

Quando profere "o sistema quer se manter no poder, o sistema não quer Bolsonaro", se refere ao sistema político e corrupto construído pelo PT, no entanto, utilizando o momento para trabalhar a ideia do salvador da pátria, ficha limpa, que não está envolvido com a corrupção. Coloca-se como o líder que vai tirar o povo do modelo opressor, e seu posicionamento não reconhece as instituições. Identifica-se, aqui, a categoria ideológica, ou seja: o parecer social foca objetivamente na ação social analisada mediante estudo social com o objetivo de caráter indicativo (ARANHA, 2003, p. 62). Uma das estratégias ideológicas utilizadas pelo PSL e pelo candidato Bolsonaro foi considerar que todo o sistema político e judiciário brasileiro é impuro. A estratégia consistia em definir e nomear os "bandidos" para, posteriormente, nomear os "defensores perfeitos". Nesse caso, a estratégia narrativa é apresentar e nomear o que é o mal do Brasil, e tratar a figura de Jair Bolsonaro como o salvador da pátria, puro e honrado, que dará até sua vida para salvar o povo. Outra narrativa ideológica complementar de seu discurso é o fato de ligar o PT a toda a corrupção brasileira. A ideologia é utilizada como ferramenta de persuasão e convencimento. O mal está no PT e nos leitores petistas. Evidente que essa é uma ideologia, porque corrupção não está apenas no PT, mas em todos os aspectos da vida brasileira. 
Após o locutor finalizar o fragmento, entra o jingle: "Dia 7 é 17!" (informação verbal”). O jingle instiga o eleitor a votar em Bolsonaro, bem como utiliza o slogan que também é o nome de sua coligação: "Brasil acima de tudo. Deus acima de todos." (informação verbal). Esse slogan é trabalhado de acordo com os princípios e valores por meio de um caráter verbal simbólico, sendo reproduzido diversas vezes pelo candidato, pelos seus apoiadores e, principalmente, nas redes sociais, construindo uma proximidade com os eleitores, onde seu efeito é tido como verdadeiro. Por meio da ideologia, o discurso é estruturado com definições profundas, fazendo com que o eleitorado apanhe determinada informação e transfira para os demais grupos, a fim de defender a importância do discurso, tendo em vista a presença ideológica (CHAUÍ, 1990, p. 21).

\section{Considerações finais}

No aspecto da construção narrativa, cada candidato optou por um discurso associado ao momento social que o Brasil vivenciava. Então, é possível perceber que o candidato Fernando Haddad (PT) se utilizou de uma estratégia ideológica de aproximação ao ex-presidente Lula, na tentativa de capitanear seus votos e sua liderança popular. A base da campanha estava na esperança e na felicidade. Por isso, o PT adotou três momentos de narrativa para produzir uma opinião pública favorável ao seu candidato. A primeira foi ligar o presidenciável Fernando Haddad com o ex-presidente Lula. Essa narrativa ideológica pretendia defender o PT e blindar o próprio Lula das acusações de corrupção. A segunda narrativa foi produzir uma ideologia em torno da felicidade e da esperança - "O povo feliz de Novo" -, que remete aos 13 anos de governo do PT. E a terceira estratégia discursiva foi a defesa da democracia, que coloca o partido como o único capaz de assegurar que os princípios e valores democráticos sejam respeitados e mantidos no Brasil.

Por outro lado, o presidenciável Jair Messias Bolsonaro (PSL) adotou uma narrativa de defesa dos valores tradicionais, colocando as ideias de família, religião e pátria como elementos fundamentais para formação de uma sociedade justa. A base é o discurso contra a corrupção - PT. Nessa órbita, coloca-se como o único candidato capaz de acabar com o "petismo" e com as ameaças do socialismo. Por outro lado, a violência 
foi utilizada para sustentar um discurso agressivo, a fim de formar uma opinião pública favorável a suas propostas. Também, estrategicamente, Bolsonaro manteve uma narrativa de defesa da família tradicional e da religião como condições de enfrentamento das ameaças e incertezas do mundo contemporâneo. Foi defensor do nacionalismo e do patriotismo como condições para o desenvolvimento do país.

Portanto, em campanhas eleitorais, as estratégias narrativas adotadas nos meios de comunicação são um dos recursos utilizados para formar uma opinião pública. A ideologia na formação de opinião pública, e na publicidade eleitoral, é um elemento central da estruturação de narrativas que discursivamente transversalizam cultural, política e economicamente. Nessa perspectiva, publicitários, marqueteiros, cientistas políticos, sociólogos e comunicólogos definem estratégias para atingir seu público alvo - o eleitor.

\section{REFERÊNCIAS}

ARANHA, Maria Lúcia de Arruda. Filosofando: introdução à filosofia. 3. ed. rev. São Paulo: Moderna, 2003.

AUGRAS, Monique. Opinião Pública: teoria e pesquisa. 2. ed. Rio de Janeiro: Petrópolis. 1974.

CHAMPAGNE, Patrick. Formar opinião: o novo jogo político. Petrópolis: Vozes, 1998.

CHAUÍ, Marilena de Sousa. O que é ideologia. 31. ed. São Paulo: Brasiliense, 1990.

FIGUEIREDO, Rubens; CERVELLINI, Sívia. O que é opinião pública. São Paulo: Brasiliense, 1996.

FIORIN, José Luiz. Linguagem e ideologia. São Paulo: Ática, 1988.

GAZETA DO POVO. Eleições 2018. Candidato: Jair Bolsonaro. 2018. Disponível em: ttps://especiais. gazetadopovo.com.br/eleicoes/2018/candidatos/presidente/jair-bolsonaro/. Acesso em: 21 set. 2018.

LASSWELL, Horold. A estrutura e a função da comunicação na sociedade. São Paulo. 1978.

MANHANELLI, Carlos Augusto. Estratégias eleitorais: marketing político. São Paulo: Summus, 1988.

MELO, J. M. D. Teoria da Comunicação: Paradigmas Latino-americanos. 4. ed. Petrópolis: Vozes, 1998.

ORLANDI, Eni Pulccinelli. Análise de discurso: princípios \& procedimentos. 6. ed. São Paulo: Pontes, 2002. 
THOMPSON, Jhon B. Ideologia e cultura moderna: teoria social crítica, na era dos meios de comunicação de massa. 8. ed. Vozes: Petrópolis, 1995.

Data do recebimento: 09 fevereiro 2019

Data da aprovação: 08 abril 2019 


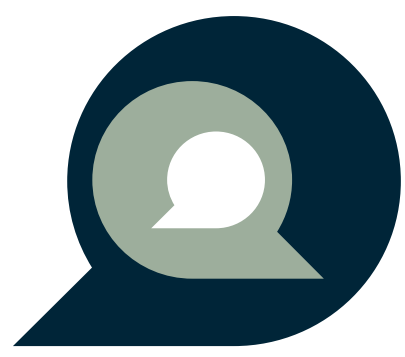

